\title{
Aborto induzido: uma comparação entre mulheres casadas e solteiras residentes na cidade de São Paulo em 2008
}

\author{
Induced abortion: a comparison between married \\ and single women residing in the city of São Paulo in 2008
}

Rebeca de Souza e Silva ${ }^{1}$ Solange Andreoni ${ }^{1}$
${ }^{1}$ Disciplina de Bioestatística, Departamento deM edicina Preventiva, Universidade Federal deSão Paulo. Rua Borges Lagoa 1341, Vila Clementino. 04038-034 São Paulo SP.

rebecaprev@globo.com
Abstract The scope of this study was to evaluate the association between having had an induced abortion and marital status (being single or legally married) in women residing in the city of São Paulo. This analysisisderived from a broader population survey on abortion conducted in 2008. In this study we focus on the subset of 389 single and legally married women between 15 and 49 years of age. Logistic regression models were used to evaluate the association between induced abortion and being single or married, monitoring age, education, income, number of live births, contraceptive use and acceptance of the practice of abortion. Being single was the only characteristic associated with having had an induced abortion, in other words, when faced with a pregnancy single women were four times more likely to have an abortion than married women ( $O R=3.9 ; p=0.009$ ). Key words Induced abortion, Marital status, Logistic regression
Resumo 0 objetivo deste estudo foi verificar a associação entre ter realizado algum aborto provocado e estado civil (ser solteira ou legalmente casada) em mulheres residentes no município de São Paulo. A presente análise é derivada de um inquérito populacional maior sobre aborto realizado em 2008. A qui enfocamos o subgrupo de 389 mulheres entre 15 e 49 anos, solteiras ou casadas legalmente. Recorreu-seà análise de regressão logística para avaliar a associação entre ter realizado aborto ou não e estado conjugal, controlandose por idade, escolaridade, renda, número de nascidos vivos, uso de métodos contraceptivos e aceitação da prática do aborto. Ser soltei ra foi a única característica associada à recorrência ao aborto provocado; isto é, diante de uma gravidez as soltei ras têm quatro vezes mais chances de aborto do queascasadas ( $O R=3,9 ; p=0,009$ ).

Palavras-chave Aborto induzido, Estado civil, Regressão logística 


\section{Introdução}

0 aborto é um tema que vem ganhando amplo destaque nesses últimos vinte anos, de tal sorte que há, atualmente, uma abundância de fontes bibliográficas sobre o tema. Estefato, em si, constitui um forte indício da sua importância para a área de saúde - sobretudo à de saúde pública, em especial a relativa à saúde sexual e reprodutiva. $M$ ais que isso, como bem enfatizam $\mathrm{H}$ ardy et $\mathrm{al}^{1}$, o aborto é um assunto debatido mundialmente, uma vez que suas motivações e consequências afetam, sob diversos aspectos - psicológicos, familiares, sociais ou econômicos, por exemplo - o cotidiano das mulheres e/ou casais que optam por tal prática.

Entende-se por aborto a interrupção da gravidez, que tanto pode advir de complicações na gestação quanto ser provocada. Segundo Rezen$\mathrm{de}^{2}$, alguns obstetras delimitam esse termo para os episódios que ocorrem até a $22^{\text {a }}$ semana da gravidez. Após esse período gestacional, a interrupção é considerada como sendo parto prematuro e no caso de óbito do feto tem-se um natimorto.

No âmbito do Brasil, a grande maioria das publicações sobre este tema é constituída de ensaios, artigos de opinião e peças argumentativas. Em média, para cada estudo baseado em evidências de pesquisas empíricas há cinco sem evidências, sendo que aquelas que as possuem são majoritariamente relativas ao campo da Saúde Pública ${ }^{3}$. Como para o campo do saber do conhecimento sobre o perfil das mulheres que optam pelo aborto provocado revela-se indispensável para prevenção dessa prática e/ou dos riscos dela decorrentes, apenas as pesquisas domiciliares, de cunho epidemiológico, desenvolvidasjunto a grupos populacionais que forneçam o norte buscado, pois permitem a avaliação dos fatores associados à referida prática.

A pesar da abundante bibliografia sobre 0 tema, os poucos estudos epidemiológicos existentes não permitem traçar deforma inequívoca um perfil das mulheres que recorrem a tal prática, quer seja pela dificuldadedese obter informações fidedignas sobre esse evento, que por ser ilegal e condenado moral mente leva a omissões voluntárias e/ou errôneas, certamente diferenciada em cada contexto estudado, quer pela falta deuniformidade entre as "medidas" e/ou condução das análises estatísticas empregadas pelos autores.

Não obstante, os resultados mais confiáveis sobre aborto no Brasil comprovam a tese de que suailegalidadetraz consequências negativas para a saúde das mulheres, pouco coíbe esta prática e perpetua a desigualdade social, uma vez que os riscos impostos pela tal ilegalidade são vividos, sobretudo, pelas mulheres menos escolarizadas, geralmente as mais pobres, e pelas que não têm acesso aos recursos médicos para o aborto segu$\mathrm{ro}^{4-6}$. Assim sendo, o status legal do aborto junto com a política pública de saúde vigente numa determinada localidade determinarão os tipos de oferta de serviços disponíveis, incluindo-se 0 aconsel hamento ea distribuição de métodoscontraceptivos, bem como o impacto da dessa prática para a saúde das mulheres que a ela recorrem ${ }^{6}$. Quanto mais restritiva é a legislação sobre aborto, mais graves e frequentes são os problemas de saúde pública decorrentes dessa prática, a ponto de 0 aborto provocado constituir-se em uma das princi pais causas de morbimortalidade materna, senão a principal como é bem o caso da maioria dos países da América Latina ${ }^{4}$.

Segundo a Organização M undial de Saúde ${ }^{6}$, nestas circunstâncias deilegalidade, 0 aborto provocado põe em perigo a vida da mulher, em decorrência das condições de risco em quesão praticados. Ou seja, épertinente argumentar queuma legislação restritiva acaba gerando discriminação e injustiça social contra as mulheres, uma vez quesó aquelas quecarecem de recursos financeiros ficam privadas de um atendimento médico adequado, diferentemente das que têm os meios suficientes para pagar um aborto seguro ou viajar para os países onde é legal ${ }^{7,8}$. M ais que isso, propicia o fortalecimento de um "mercado clandestino" de serviços, de sorte a favorecer a proliferação dos de alto risco ${ }^{7,9-12}$. Dificulta, ainda, a obtenção de informação fidedigna sobre a prática do aborto, o que ocasiona uma subestimação da magnitude do induzido em geral - ou pela omissão deliberada da sua provocação, ou pela por omissão errônea, referindo-a como espontânea; além de afetar a precisão e a veracidade de informações sobre aspectos específicos relacionados com esta prática, tais como as razões e o mecanismo utilizado para interromper a gravidez, as consequências decorrentes de tal prática, entre muitos outros ${ }^{13,14}$.

Assim sendo, a investigação do aborto nessa situação de ilegalidade requer cuidados metodológicos específicos, com implicações éticas no manejo do tema ${ }^{15}$.

No cenário mundial, segundo dados do Center for Reproductive Law and Policy ${ }^{16}, 40,5 \%$ da população mundial viveem 54 países quepermitem o abortamento sem restrições; $20,7 \%$ da população mundial vivem em 14 países que per- 
mitem 0 aborto com base em razões sociais e econômicas; outros $12,8 \%$ vivem em 55 países que permitem 0 abortamento quando necessário para a saúde da gestante, e apenas os $26 \%$ restantes vivem em 72 países que proíbem o abortamento ou o permitem apenas em casos de risco a vida da gestante. 0 Brasil enquadra-se, portanto, entre a minoria de legislação mais restritiva - conforme os artigos 124 a 128 do Código Penal Brasileiro ${ }^{17}$, a penalidade para as mulheres que se submetem a um aborto de forma ilegal varia de 1 a 10 anos de prisão, com pena duplicada para aqueles que o praticaram ou 0 auxiliaram. No país, o aborto só é permitido se for 0 último recurso para salvar a vida da mãe ou se a gravidez resultar de um estupro. É bem verdade que há jurisprudência para o caso de fetos anencefálico, mas esta é implementada somente por poucos médicos mais engajados na luta pela le galização. Como não poderia deixar de ser, entretanto, Adesse et al. ${ }^{18}$, numa pesquisa sobre a magnitude do aborto no Brasil, confirmam que sua tipificação como um delito em si não desestimula as mulheres a se submeterem ao mesmo, pelo contrário, as incentiva à prática de risco. M ostra, ainda, que existem diferenças socioeconômicas, culturais e regionais diante da mesma ilegalidade. Mulheres com melhores condições financeiras, geralmente nos grandes centros urbanos, têm acesso aos métodos e clínicas ilegais com mel hores condições dehigienee cuidado. Já as mais carentes, consideradas a grande maioria da população feminina brasileira, recorrem aos métodos mais perigosos, com pouca precaução, resultando num alto índice de agravos à saúde.

O estado civil, segundo Silva e Vieira ${ }^{19}$ se mostrou o único fator responsável para uma maior prevalência de abortos provocados na $\mathrm{Ci}$ dade de São Paulo em 1993. M ais precisamente, o contraste entre as mulheres casadas legal mente e as solteiras revelou que nenhuma das outras características sociodemográficas investigadas mostrou-se associada à provocação de um aborto. Contudo, entre as casadas legalmente a pre valência de aborto provocado foi dez vezes menos que a observada entre as solteiras.

Várias são as hipóteses que podem ser aventadas para explicar tal resultado, entre elas a de que as mulheres casadas além possuírem um maior leque de alternativas contraceptivas, inclusivea esterilização, émais fácil, a dois, seoptar pela continuidade de uma gestação, mesmo que esta não tenha sido desejada/planejada. Em contrapartida, as mulheres solteiras, além de mais expostas a uma gravidez inoportuna - tanto pelo caráter instável das relações afetivas, quanto pela menor disponibilidade de métodos contraceptivos adequados - têm maior dificuldade em fazer a opção de continuidade da gestação e, consequentemente, optam em maior medida pelo aborto provocado.

Contudo, independentementedas justificativas que se possa aventar para explicar o referido desencontro, o fato é que a dimensão dessa discrepância nos obriga a refletir com seriedade sobre o papel do estado civil na opção pelo aborto provocado.

N este sentido, a partir de dados recentes, coletados na mesma região geográfica anal isada por Silva e Vieira ${ }^{19} \mathrm{com} 15$ anos de anterioridade, 0 objetivo do presente trabalho é o de comparar a ocorrência de aborto provocado entre mulheres casadas no civil ou religioso com a de mulheres solteiras - com ou sem companheiro sexual -, residentes na cidade de São Paulo, no último trimestre de 2008.

\section{M aterial e $M$ étodo}

Trata-se de um estudo transversal no qual foram entrevistadas, por sorteio aleatório, cerca de 1200 mulheres de 15 a 59 anos de idade Para tanto, partindo de mapas obtidos na Empresa Paulista de Planejamento M etropolitano (Emplasa), foram sorteadas 120 ruas da Cidade de São Paulo, em cada uma destas foram visitados 10 domicílios e em cada um foi sorteada uma mulher na idade de interesse. Todas as informações foram obtidas mediante entrevista face a face e por pesquisadoras treinadas. A saber, Silva e Vieira ${ }^{19}$ utilizaram estratégia amostral equivalente.

Para o presente artigo, entretanto, o foco de interesse é analisar apenas as mulheres em idade fértil (entre 15 e 49 anos de idade) que estavam casadas - no civil e/ou religioso, ou solteiras com ou sem parceiro sexual - no momento da entrevista (544), mais precisamente, as 389 que declararam alguma gestação. Isso permite, portanto, uma comparação direta com os achados de 1993.

Além de estado conjugal, outras informações foram coletadas e reagrupadas para a análise AM apreço da seguinte forma: idade por grupo quinquenal; exercer ou não alguma atividaderemunerada; renda familiar mensal categorizada em 8 níveis al ém da não resposta; escolaridade categorizada em 5 níveis; tipo de método contraceptivo atual, pílula ou DIU, esterilização, outros menos eficazes que a pílula ou DIU e nenhum método; 
aceitar ou não a provocação de um aborto em alguns quesitos pontuais - pergunta que admitia respostas múltiplas e partia do questionamento sobre as situações em que a entrevistada consideraria aceitável a provocação de um aborto etinha como alternativas os motivos previstos por lei (risco iminente de morte da mãe e estupro) ealternativas como a mulher ser solteira ou não se ter condições financeiras de criar o filho, entre outras - categorizada em não aceita em qualquer situação, aceita em situações restritas - pelos motivos previstos em lei, risco de vida do feto ou em al guma outra situação extrema - eaceita sempre, qualquer que seja o motivo da mulher; e número de nascidos vivos em 5 categorias.

Neste ponto, vale ressaltar, que foi impossível se trabalhar com a variável número desejado de filhos, a qual se destacou na comparação dos perfis de mulheres solteiras e casadas no trabaIho publicado anteriormente ${ }^{19}$. Por ocasião do pré-teste, a maioria das respostas à pergunta "quantos filhos você considera ideal se ter nos dias atuais?" era muito evasiva. Por exemplo: ainda não pensei no assunto, não estou preocupada com filhos esim com a relação com meu companheiro, vai depender do meu momento de vida, vai depender do apoio de meu companheiro ou agora já não me preocupo mais com isso.

Num primeiro momento são apresentadas as características demográficas das 389 mulheres alvo deste estudo e as possíveis diferenças estatísticas existentes entre casadas e solteiras quanto às outras características sociodemográficas são avaliadas pelo teste generalizado de Fisher. Para os dois grupos de mulheres - casadas e solteiras - é avaliado, ainda, por meio da análise de variância, se há diferenças entre as médias de idadee no número de nascimentos vivos no momento da entrevista.

Por outra parte, para a análise de regressão logística, a variável resposta adotada éter ou não declarado algum aborto provocado ( 1 sim e 0 não), e as independentes supracitadas são dicotomizadas em: renda mensal familiar abaixo de 2 salários mínimos (SM ) e acima de 2 SM ; escolaridade até o nível fundamental II ou acima disso; usar ou não algum método contraceptivo; aceitar a prática do aborto em qual quer situação ou não; e ser casada ou solteira. Para a idade e o número de nascidos vivos foram utilizados os valores originais.

Foram consideradas como significativas para o modelo final as variáveis que apresentassem $p<0,05$. As análises estatísticas foram realizadas utilizando o programa SPSS, version 15.0.

\section{Resultados}

A primeira constatação é a de que houve uma subestimação de mulheres dos dois primeiros grupos quinquenais de idade- 15 a 19 anos e 20 a 24 anos. Com efeito, entre as 544 mulheres casadas esolteiras entrevistadasinicialmente, com idades entre 15 e 49 anos completos, os dois primeiros grupos etários juntos agregaram somente $10,2 \%$ das mulheres entrevistadas ao invés dos esperados $13 \%$ em cada grupo etário. Os dados da FSEADE ${ }^{20}$ indicam que a proporção de muIheres em idade fértil é distribuída quase uniformementeentreos 7 gruposquinquenais deidade, mais precisamente, há entre 12 e $14 \%$ demulheres em cada faixa etária. Como nestas, geralmente ainda não estão casadas, isso pode levar a uma subestimação de solteiras, mas no caso específico daquelas com gestação, possivelmente, haverá uma pequena perda de aborto provocado.

Na Tabela 1 são apresentadas as características demográficas das 389 mulheres com gestação, alvo deste estudo e as possíveis diferenças existentes entre solteiras e casadas. Observa-se, por exemplo, que não há diferença estatística entre elas ao se contrastar o estado civil - casadas (320) e solteiras (69) - com respeito à idade no momento da entrevista $(p=0,100)$ e, tampouco com respeito à aceitação do aborto $(p=0,326)$. Contudo, existe comportamento diferencial por estado civil nos quesitos atividade remunerada, renda mensal e escolaridade. Uma maior proporção de solteiras exerce tarefas remuneradas ( $p<0,001)$, contudo as solteiras possuem renda familiar menor $(p=0,001)$ havendo uma maior concentração de solteiras com renda abaixo de $\mathrm{R} \$ 726,26$ (aproximadamente 1,5 salários mínimos); e, também, são menos escolarizadas $(p=0,037)$ com uma menor proporção superando o ensino fundamental. Com respeito ao uso de métodos contraceptivos no momento da entrevista, observa-se na Tabela 1 que a diferença estatística no comportamento de solteiras e casadas é limítrofe $(p=0,055)$. Observa-se que a proporção de não usuárias de contraceptivos, por exemplo, é muito si milar entre casadas e solteiras - cerca de $27 \%$. Dentre as solteiras, possivelmente, existe uma parcela de mulheresquenão possuem vida sexual ativa. Dentreas casadas, em contrapartida, éprovável quehaja um grupo que esteja buscando uma gestação. Contudo, entre as solteiras há um predomínio de usuárias de métodos contraceptivos menos eficazes - apontando para o caráter instável de eventuais relações sexuais - e entre as mulheres casadas uma 
Tabela 1. Características das mulheres que engravidaram por estado civil.

\begin{tabular}{|c|c|c|c|c|c|c|c|}
\hline \multirow{3}{*}{ Característica } & \multicolumn{4}{|c|}{ Estado civil } & & & \multirow{3}{*}{ Fisher $p$} \\
\hline & \multicolumn{2}{|c|}{ Casada } & \multicolumn{2}{|c|}{ Solteira } & \multicolumn{2}{|c|}{ Total } & \\
\hline & $\mathrm{n}$ & $\%$ & $\mathrm{n}$ & $\%$ & $n$ & $\%$ & \\
\hline Total & 320 & 100,0 & 69 & 100,0 & 389 & 100,0 & \\
\hline Idade & & & & & & & 0,100 \\
\hline 15 a 19 & 3 & 0,9 & 3 & 4,3 & 6 & 1,5 & \\
\hline 20 a 24 & 17 & 5,3 & 5 & 7,2 & 22 & 5,7 & \\
\hline 25 a 29 & 48 & 15,0 & 14 & 20,3 & 62 & 15,9 & \\
\hline 30 a 34 & 63 & 19,7 & 9 & 13,0 & 72 & 18,5 & \\
\hline 35 a 39 & 57 & 17,8 & 11 & 15,9 & 68 & 17,5 & \\
\hline 40 a 44 & 70 & 21,9 & 9 & 13,0 & 79 & 20,3 & \\
\hline 45 a 49 & 62 & 19,4 & 18 & 26,1 & 80 & 20,6 & \\
\hline Trabalha & & & & & & & $<0,001$ \\
\hline Não & 183 & 57,2 & 22 & 31,9 & 205 & 52,7 & \\
\hline Sim & 137 & 42,8 & 47 & 68,1 & 184 & 47,3 & \\
\hline Renda & & & & & & & 0,001 \\
\hline até $R \$ 276,70$ & 11 & 3,4 & 7 & 10,1 & 18 & 4,6 & \\
\hline de $R \$ 276,71$ a $R \$ 484,97$ & 16 & 5,0 & 11 & 15,9 & 27 & 6,9 & \\
\hline de $R \$ 484,98$ a $R \$ 726,26$ & 42 & 13,1 & 15 & 21,7 & 57 & 14,7 & \\
\hline de $R \$ 726,27$ a $R \$ 1.194,53$ & 93 & 29,1 & 17 & 24,6 & 110 & 28,3 & \\
\hline de $R \$ 1.194,54$ a $R \$ 2.012,67$ & 75 & 23,4 & 10 & 14,5 & 85 & 21,9 & \\
\hline de $R \$ 2.012,68$ a $R \$ 3.479,36$ & 40 & 12,5 & 4 & 5,8 & 44 & 11,3 & \\
\hline de $R \$ 3.479,37$ a $R \$ 6.563,73$ & 24 & 7,5 & 2 & 2,9 & 26 & 6,7 & \\
\hline acima de $\mathrm{R} \$ 6.563,74$ & 7 & 2,2 & 1 & 1,4 & 8 & 2,1 & \\
\hline Não Respondeu & 12 & 3,8 & 2 & 2,9 & 14 & 3,6 & \\
\hline Escolaridade & & & & & & & 0,037 \\
\hline $\begin{array}{l}\text { Analfabeta, saber ler e } \\
\text { escrever, primário } \\
\text { incompleto ou completo }\end{array}$ & 42 & 13,1 & 11 & 15,9 & 53 & 13,6 & \\
\hline $\begin{array}{l}\text { Ginásio, fundamental } \\
\text { incompleto ou completo }\end{array}$ & 64 & 20,0 & 24 & 34,8 & 88 & 22,6 & \\
\hline $\begin{array}{l}\text { Colegial, médio incompleto } \\
\text { ou completo }\end{array}$ & 161 & 50,3 & 27 & 39,1 & 188 & 48,3 & \\
\hline $\begin{array}{l}\text { Superior incompleto ou } \\
\text { completo }\end{array}$ & 53 & 16,6 & 7 & 10,1 & 60 & 15,4 & \\
\hline M étodo Contraceptivo Atual & & & & & & & 0,055 \\
\hline Pílula ou DIU & 71 & 22,2 & 20 & 29,0 & 91 & 23,4 & \\
\hline Esterilização Eletiva & 69 & 21,6 & 6 & 8,7 & 75 & 19,3 & \\
\hline M enos Eficaz & 93 & 29,1 & 25 & 36,2 & 118 & 30,3 & \\
\hline Não Usa & 87 & 27,2 & 18 & 26,1 & 105 & 27,0 & \\
\hline Aceita Aborto & & & & & & & 0,326 \\
\hline Não aceita & 133 & 41,6 & 34 & 49,3 & 167 & 42,9 & \\
\hline Aceita alguma & 173 & 54,1 & 31 & 44,9 & 204 & 52,4 & \\
\hline Aceita sempre & 14 & 4,4 & 4 & 5,8 & 18 & 4,6 & \\
\hline Número de Nascidos Vivos & & & & & & & $<0,001$ \\
\hline 0 & 10 & 3,1 & 11 & 15,9 & 21 & 5,4 & \\
\hline 1 & 94 & 29,4 & 27 & 39,1 & 121 & 31,1 & \\
\hline 2 & 111 & 34,7 & 14 & 20,3 & 125 & 32,1 & \\
\hline 3 & 63 & 19,7 & 10 & 14,5 & 73 & 18,8 & \\
\hline 4 ou mais & 42 & 13,1 & 11 & 15,9 & 49 & 12,6 & \\
\hline
\end{tabular}

alta proporção de esterilizações, cerca de $22 \%$, indicando que pelo menos um quinto das muIheres casadas com alguma gestação já atingi- ram a fecundidade desejada. Por fim, com respeito ao número de nascimentos vivos, 15,9\% das mulheres solteiras com al guma gestação não 
possuía filhos contra apenas 3,1\% das mulheres casadas (Tabela 1).

As solteiras possuem em média 1,77 filhos com desvio padrão de 1,57 filhos contra os 2,17 filhos com desvio padrão de 1,25 filhos das casadas (Tabela 2). Para os efeitos dos padrões de fecundidadeatual, entretanto, essa diferença não chama a atenção. A Tabela 2 revela que embora a idade das mulheres com al guma gestação no momento da entrevistanão difira estatisticamente entre as solteiras e as casadas, todas possuem em média 37 anos de idade, as solteiras possuem uma média de filhos nascidos vivos inferior à anotada entre as casadas.

Que explicação poderíamos encontrar para a similaridade com respeito à idade no momento da entrevista concomitantemente a uma discrepância no número de nascidos vivos? A primeira é a de que o caráter instável das relações afetivas das solteiras as levaria a usar menos frequentementemétodos contraceptivos eficazese, por conseguinte, as colocaria em maior escala diante de uma gravidez não desejada ou não planejada. A segunda, que também corrobora com aquela hipótese, é que disporiam de menos acesso e/ou menos informação sobre métodos contraceptivos. Vem de encontro a esse argumento o fato de a Tabela 1 revelar a existência de comportamento diferencial por estado civil nos quesitos atividade remunerada, renda mensal e escolaridade. Uma maior proporção de solteiras exercetarefas remuneradas, mas possui renda familiar menor e são menos escolarizadas. Esse achado reforça a hipótese de maior dificuldade de acesso ou menor conhecimento sobre os métodos contraceptivos.

Estar ou não casada foi fortemente associado à maternidade, já que $16 \%$ das mulheres solteiras
Tabela 2. M édias e desvios padrão de número de nascidos vivos e idade segundo estado civil.

\begin{tabular}{|c|c|c|c|c|}
\hline & \multicolumn{2}{|c|}{ Estado civil } & \multirow[b]{2}{*}{ Total } & \multirow[b]{2}{*}{$\mathrm{p}$} \\
\hline & Casada & Solteira & & \\
\hline Idade (anos) & & & & 0,331 \\
\hline $\mathrm{n}$ & 320 & 69 & 389 & \\
\hline M édia & 37,13 & 36,09 & 36,94 & \\
\hline Desvio Padrão & 7,77 & 9,08 & 8,01 & \\
\hline Mín-Máx & $18,43-49,95$ & $16,49-49,39$ & $16,49-49,95$ & \\
\hline Nascidos Vivos & & & & 0,021 \\
\hline $\mathrm{n}$ & 320 & 69 & 389 & \\
\hline M édia & 2,17 & 1,77 & 2,1 & \\
\hline Desvio Padrão & 1,25 & 1,57 & 1,32 & \\
\hline Mín-Máx & $0-9$ & $0-8$ & $0-9$ & \\
\hline
\end{tabular}

com al guma gestação não possuem filhos contra $3,1 \%$ das casadas. Não há motivos para se suspeitar que solteiras tenham maior probabilidade de uma perda natural. Isso pode indicar dificuldades ao se deparar com uma gestação na ausência de um companheiro fixo, já que as solteiras com gestação tiveram renda familiar mais baixa. A ocorrência de gestações entre as mulheres solteiras estaria, portanto, associada a uma baixa renda mensal? Provavelmente não. 0 que deve estar associado à baixa renda de mulheres solteiras é a forma de resolução da gestação. Reforça esse argumento, o fato apontado acima de que não há diferença entrea média de idades desolteiras e casadas. Ou seja, outra constatação de uma sub-representação demulheres jovens e solteiras.

Sobressai, portanto, o primeiro indício deque as mulheres solteiras podem recorrer em maior medida que as casadas ao aborto provocado. E, no mínimo, nos coloca diante da seguinte questão: Enquanto pesquisadores da área de saúde pública, quem devemos privilegiar na atenção à saúde sexual e reprodutiva, as mulheres casadas ou as solteiras? Dito de outra forma, as categorias de mulheres que apontam um maior montante de aborto ou aquelas mais propensas a abortar?

Dado esse perfil das mulheres casadas e solteiras, na Tabela 3 apresenta-se o modelo inicial de regressão logística utilizado para descrever as características dessas mulheres quanto a já ter tido algum aborto induzido. Na Tabela 3 observa-se que a única variável que tem associação estatística com a presença de aborto(s) provocado(s): é ser solteira, com um $\mathrm{OR}=4,26$ $(p=0,011)$.

Desta feita, na Tabela 4 apresenta-se o modelo reduzido deregressão logística. O bserva-seque, coerentemente, o valor da razão de chances das solteiras - $O R=3,90(p=0,009)$ - não sofre alte-

Tabela 3. Modelo inicial de regressão logística para ter realizado aborto.

\begin{tabular}{lccc}
\hline \multicolumn{1}{c}{ Variáveis } & OR* & IC95\%** & $\mathrm{p}$ \\
\hline Solteira & 4,26 & {$[1,39 ; 13,04]$} & 0,011 \\
Usa método & 1,41 & {$[0,41 ; 4,76]$} & 0,591 \\
contraceptivo & & & \\
Renda baixa & 1,81 & {$[0,55 ; 5,94]$} & 0,328 \\
Escolaridade baixa & 0,56 & {$[0,16 ; 1,89]$} & 0,348 \\
Nascidos vivos & 0,94 & {$[0,61 ; 1,46]$} & 0,793 \\
Idade & 1,05 & {$[0,98 ; 1,13]$} & 0,166 \\
Aceita aborto & 2,78 & {$[0,84 ; 9,09]$} & 0,095 \\
\hline
\end{tabular}


Tabela 4. Distribuição de mulheres que engravidaram por aborto provocado entre solteiras e casadas.

\begin{tabular}{|c|c|c|c|c|c|c|c|c|c|}
\hline \multirow{3}{*}{ Estado civil } & \multicolumn{6}{|c|}{ Aborto provocado } & \multirow{3}{*}{ OR* } & \multirow{3}{*}{ IC $95 \% * *$} & \multirow{3}{*}{$\mathrm{p}$} \\
\hline & \multicolumn{2}{|c|}{ Não } & \multicolumn{2}{|c|}{ Sim } & \multicolumn{2}{|c|}{ Total } & & & \\
\hline & $n$ & $\%$ & $n$ & $\%$ & $n$ & $\%$ & & & \\
\hline Casada & 311 & 97,2 & 9 & 2,8 & 320 & 100,0 & & & \\
\hline Solteira & 62 & 89,9 & 7 & 10,1 & 69 & 100,0 & 3,90 & {$[1,40 ; 10,87]$} & 0,009 \\
\hline Total & 373 & 95,9 & 16 & 4,1 & 389 & 100,0 & & & \\
\hline
\end{tabular}

* OR = Razão deChances; ** IC 95\% - Intervalo de Confiança de 95\%.

ração. Em suma, a prática de aborto provocado entre as solteiras é o quádruplo da observada entre casadas. Essa discrepância, embora elevada, está bem aquém do observado por Silva e Vieira ${ }^{19}$. Reforçando, uma vez mais, a hipótese de subestimação de abortos provocados atrelados às jovens e solteiras. A proporção de mulheres com aborto provocado é de $2,8 \%$ entre as casadas e de $10,1 \%$ entre as solteiras (Tabela 4).

\section{Conclusões eDiscussão}

Embora a grande limitação desse estudo seja a subrepresentatividade de mulheres jovens, provavel mente solteiras e com um número de filhos bem reduzido, senão nulo, como aponta os achados de pesquisas anteriores ${ }^{21-24}$, com consequentesubnotificação de abortos provocados, os achados aqui obtidos nos obrigam a refletir com seriedade sobre o papel do aborto provocado num cenário de baixa fecundidade e recursos contraceptivos ainda bem limitados.

Por outro lado, o fato de não conseguirmos localizar as mulheres mais jovens em casa, mesmo realizando as entrevistas no período noturno enos finais de semana, pode ser um indicativo de que essas mulheres jovens morem só. Provavelmente não têm filhos, e ou passam a maior parte de seus tempo fora de casa - estudando, trabalhando, buscando trabalho ou que por medidas de segurança, não quiseram que se soubesse da presença delas na casa e optaram por não atender a porta.

Reforça 0 argumento de que as solteiras não localizadas vivam sozinhas a reação mostrada no questionamento sobre "quantos filhos você considera ideal nos dias de hoje?" Ele revela, se examinado com cautela, que a maternidade não parece mais ser um tema prioritário ou indispensável na condução da vida da mulher moderna. Hojeem dia, ao quetudo indica, uma parcela substantiva das mulheres está se realizando em outros terrenos que não unicamente 0 da maternidade e, via de regra, postergam a maternidade e priorizam o trabalho e os estudos.

Em trabal ho realizado por Silva eFusco ${ }^{25}$ entre adolescentes residentes numa favela ficou evidenciado que mesmo entre as jovens de baixa renda, estudar, conseguir um bom trabal ho e poder comprar a casa própria eram muito mais importantes do que casar ou ter filhos. N ão obstante, o casamento ainda era visto, por aqueles jovens, como o caminho mais acertado para se construir uma família e criar os filhos.

Mesmo considerando o elevado número de mulheres chefes de família ${ }^{26}$ e um número expressivo quecriam seus filhos sem a ajuda do pai da criança, parece muito sugestivo que a presença de um companheiro fixo favoreça um nascimento. Quer mediante o devido planejamento de uma gravidez ou pela maior facilidade de se levar a termo uma gestação não planejada.

Nesse cenário, não é de surpreender que a proporção de mulheres solteiras com abortos provocados tenha se revelado quatro vezes superior ao de mulheres casadas legalmente. Ao contrário, Silva eV ieira ${ }^{19}$ encontrarauma discrepância muito mais acentuada, pois em 1993 as solteiras procavam o décuplo de aborto que as muIheres casadas.

Essa atenuação da discrepancia entre casadas e solteiras por um lado pode ser justificado pela acentuada redução da fecundidade ocorrida na região nos últimos 15 anos $^{27}$; por outro lado, pode estar revelando que as mulheres solteiras estão logrando maiores êxitos em previnir uma gravidez não planejada, reflexo, certamente, dos programas de saúde reprodutiva que vêm sendo implementados e que possibilitam a obtenção gratuita ou a preço reduzido de contraceptivos, sobretudo a pílula e o condom ${ }^{15}$.

0 que surpreende, de al guma forma, éo fato de o estado conjugal ser o único fator a explicar a 
recorrência ao aborto. Em 1993, Silva e Vieira ${ }^{19}$ constataram que o número reduzido de nascimentos vivos e a idade precoce da mulher - ter entre 15 e 19 anos - também eram fatores decisivos para a provocação de um aborto. Ressalte se, contudo, que as referidas autoras não lançaram mão de uma análise multivariada.

Ao que tudo indica, portanto, a idade da mulher não mais se revela em fator preponderante para a recorrência ao aborto provocado, possivelmenteem decorrência da postergação do casamento. Com efeito, Carneiro ${ }^{21}$ constatou, por exemplo, queas mulheres sem nascidos vivos são as que mais recorrem ao aborto provocado independentemente de suas idades. 0 reduzido número denascidos vivos, ao contrário, tem persistentemente se associado a uma maior recorrência ao aborto provocado, sobretudo pelo fato de a primeira gravidez ocorrer de forma mais inesperada e da precocidade da idade em que se inicia a vida sexual ${ }^{21-24,28}$. É possível, contudo, que a perda de mulheres jovens com uma única gestação terminada em aborto justifique o fato de esse fator não ter se mostrado isignificante.

Seja como for, seria ingenuidade supor que o aborto provocado deixará de ter papel de destaque entre as mulheres que engravidam inesperadamente. Nossos achados, revelam que essa situação é mais propícia entre as mulheres solteiras e, talvez, sem filhos nascidos vivos.

Segundo Diniz ${ }^{4}$, ao contrário do senso comum, muitas mulheres que provocam aborto são casadas ou vivem em união estável, geralmente têm vários filhos e podem usar 0 aborto como meio de limitar o tamanho da família ou espaçar nascimentos, quando acontece falha do método contraceptivo em uso ou pela falta de acesso a métodos contraceptivos seguros ${ }^{7}$. O bviamente, essa situação reflete sobretudo às das camadas mais pobres, por se constituírem na grande maioria da população brasileira.

Nesse sentido, recentemente, Diniz e M edei$\operatorname{ros}^{29}$, em pesquisa realizada nas regiões urbanas do Brasil, apontou ser as mulheres menos escolarizadas - muito provavelmente, as mais pobres as que mais recorrem ao aborto provocado.

0 padrão de fecundidade baixa vem se consolidando naCapital paulistadesdemeados de $1985^{27}$. Pode-se aventar a hipótese, pautando-se na crescente participação feminina no mercado de trabaIho ena busca de identidade das mesmas, que não tardará em que esse perfil setorne realidadenacional. Se por um lado, a inserção feminina nas altas efferas do poder - gerência, chefia, ministério, entre outros - facilitará a incorporação e o uso de métodos contraceptivos eficazes em suas rotinas; por outro, o reduzido leque de possibilidades contraceptivasaliado aosdanosos efeitos colaterais dos poucos métodos existentes acabará por elevar a probabilidade de as mulheres solteiras provocarem um aborto. Ademais, dentro de uma relação estável é mais provável a 'programação' de uma gestação e quase que, seguramente, nessa situação uma gravidez é mais desejável.

Ao nosso ver, portanto, serão as mulheres solteiras as maiores candidatas a provocar um aborto até que as alternativas contraceptivas sejam mais numerosas e mais inócuas. Certamente, as que lançarem mão de técnicas seguras e buscarem um profissional qualificado estarão menos expostas às sequelas decorrentes do referido procedimento. Não obstante, essa solução não está no alcance financeiro de muitas mulheres. Com efeito, num panorama como o brasileiro, onde o aborto provocado é criminalizado - à exceção do terapêutico, permitido como último recurso para salvar a vida da mãe e do resultante deestupro - em queas clínicas clandestinas cobram um preço exorbitante, uma grande parcela das mulheres se submete a procedimentos pouco confiáveis em termos de higiene ou mesmo opta pela autoprovocação do aborto.

É bem verdade que o uso do misoprostol contribui enormemente para a redução das sequelas pós-aborto. Contudo, a falta de informação adequada sobre seu correto uso, sobretudo entre as mulheres de baixa classe social, leva a que esse medicamento não atinja plenamente seus ben efícios. Em suma, as mulheres solteiras recorrem proporcionalmente mais a um aborto provocado, mas, a nosso ver, esta peculiaridade tenderá a ser cada menos acentuada.

Contudo, as mais pobres, com menor escolaridade e maior dificuldade de acesso às benesses do mundo moderno, continuarão pagando um alto preço - que podeser suas próprias vidas - pela opção de provocar um aborto. Esse impasse só será resolvido se o acesso aos serviços de qualidade for equitativo e, para tanto, há que se legalizar o aborto no país.

\section{Colaboradores}

RS Silva e S Andreoni participaram igualmente de todas as etapas de elaboração do artigo. 


\section{Referências}

1. Hardy E, Costa RG, Rodrigues T, Moraes TM. Características atuais associadas à história de aborto provocado. Rev Saude Publica 1994; 28(1):82-85.

2. Rezende M. Obstetrícia Fundamental. $11^{\circ} \mathrm{Ed}$. Rio de Janeiro: Guanabara Koogan; 2008.

3. Brasil. Ministério da Saúde (MS). Secretaria de Ciência, Tecnologia e Insumos Estratégicos. Departamento de Ciência e tecnologia. Aborto e Saúde Pública: 20 anos de Pesquisas no Brasil. Brasília: M S; 2009.

4. Diniz M. Aborto e Saúde Pública no Brasil. Cad Saude Publica 2007; 23(9):1992-1993.

5. Llovet JJ, Ramos S. El estudio del aborto inducido en America Latina: Un balance parcial y algunas propuestas a futuro [Study of induced abortion in Latin America: A partial evaluation and some proposals for the future]. In: Stern C, Figueroa JG, editors. Sexualidad y salud reproductiva: Avances y retos para la investigacion [Sexuality and reproductive health: Advances and challenges for research]. M exico: El Colegio de Mexico; 2001. p. 285-322.

6. Organização M undial da Saúde (OMS). Abortamento seguro: orientação técnica e de políticas para os sistemas de saúde. Genebra: OM S; 2004.

7. Casas Becerra L. M ujeres procesadas por aborto. Santiago de Chile: Foro Abierto de Salud y Derechos Reproductivos 106; 1996.

8. Centro de derechos reproductivos. Encarcerladas: leyes contra el aborto en Chile. Un análisis desde los derechos humanos. Nova Iorque: Centro de derechos reproductivos; 1998. p. 113.

9. Kulczycki A. De eso no se habla: aceptando el aborto en M éxico. Estudios demograficos y urbanos 2003; 18(2):353-386.

10. Center for Reproductive Law and Policy. Making Abortion Safe, Legal and Accessible: A Tool Kit for Action. Nova Iorque: Center for Reproductive Law and Policy; 2000.

11. Pine RN . Achieving public health objectives through family planning services. Reproductive $\mathrm{H}$ ealth $\mathrm{M}$ atters 1993; 1(2):77-83.

12. Guzmán V. La equidad de género como tema de debate y de políticas públicas. In: Largo E. Genero en el Estado - Estado del Genero. Chile: Ediciones de las M ujeres $n^{\circ} 27$, Isis Internacional; 1998.

13. Guillaume A, Molmy W. Abortion in Africa. A review of literature from the 1990's to the present day. Les Numériques du CEPED (french \& english), Paris: CEPED; 2004.

14. Blayo C. Mourir d'avortement. Facteurs politiques et sociaux. 1998 - Morbidité, mortalité: problèmes de mesure, facteurs d'évolution, essai de prospective. In: Colloque International de Sinaia, 1996, Paris; PUF. p. 318-326.

15. Menezes $G$, Aquino EM L. Pesquisa sobre 0 aborto no Brasil: avanços e desafios para o campo da saúde coletiva. Cad Saude Publica 2009; 25(Supl. 2):s193s204.

16. Center for Reproductive Law and Policy (CRLP). Abortion. Reproductive Rights 2000: Moving Forward. Nova I orque: CRLP; 2000. p. 25-31.

17. Brasil. Código Penal: Decreto lei n. 1.004, de 21 de outubro de 1969. $4^{\text {a }}$ ed. São Paulo: Saraiva; 1971.
18. Adesse L, M onteiro M FG, Levin J. Abortamento, um grave problema de saúde pública e de justiça social.Revista Radis - Comunicação em Saúde 2008; 66:10-15. [acessado 2009 abr 11]. Disponível em: http://www.ensp.fiocruz.br/radis/sites/default/files/ radis $66 . p d f$

19. Silva $\mathrm{RS}$, Vieira EM. Aborto provocado: sua dimensão e características entre mulheres solteiras e casadas da cidade de São Paulo, Brasil. Cad Saude Publica 2009; 25(1):179-187.

20. Fundação Sistema Estadual de Análise de Dados (FSEADE). Secretaria de Economia e Planejamento. Perfil M unicipal de São Paulo, 2009. [acessado 2012 jun 2]. Disponível em: http://www.seade.gov. br/produtos/perfil/perfil.php

21. Carneiro MCMO. Prevalência e características das mulheres com histórico de aborto - Vila mariana, 2006 [dissertação]. São Paulo: Universidade Federal de São Paulo; 2009.

22. Silva RS. Aborto provocado: sua incidência e características. Um estudo com mulheres em idade fértil (15 a 49 anos), residentes no subdistrito de Cidade de São Paulo [tese]. São Paulo: Universidade de São Paulo; 1992.

23. Santos EBC. Aborto induzido: ocorrência e características no antigo sub-distrito de Vila M adalena, São Paulo, Brasil -2000 [tese]. São Paulo: Universidade Federal de São Paulo, Escola Paulista de Medicina; 2005.

24. M aldonado MTM. Fatores associados ao aborto provocado em mulheres em idade fértil com histórico de gestação - São Paulo [dissertação]. São Paulo: Universidade Federal de São Paulo; 2006.

25. Silva RS, Fusco $C$. Aborto provocado: uma realidade ilegal. In: M iranda-Ribeiro P, Simão $A B$, organizadores. Qualificando os números: estudos sobre saúde sexual e reprodutiva no Brasil. Demografia em Debate V. 2; 2008. p. 185-204.

26. Instituto Brasileiro de Geografia e Estatística (IBGE). Censo Demográfico 2010. Primeiros Resultados do Censo 2010. Rio de Janeiro: IBGE; 2010.

27. Yasaki LM. Análise da Fecundidade no Estado de São Paulo SP. São Paulo perspect 2008; 22(1):48-65.

28. Santos TF. Prevalência e características de mulheres com aborto provocado na favela M éxico 70 , São Vicente - SP [dissertação]. São Paulo: U niversidade Federal de São Paulo; 2010.

29. Diniz D, Medeiros M. Aborto no Brasil: uma pesquisa domiciliar com técnica de urna. Cien Saude Colet 2010; 15(Supl. 1):959-966.

Artigo apresentado em 14/03/2012

Aprovado em 25/03/2012

Versão final apresentada em 29/03/2012 